\title{
Cognitive Emotion Regulation of Teachers In Relation To Their Gender and Experience
}

\author{
K.P.Shanmuga vadivu * \\ * Assistant professor of education, Sri Sarada College of Education, Salem.
}

\begin{abstract}
Everybody deals with negative, unpleasant and stressful events from time to time in every field. And they respond to their own way .Especially teaching profession is multidimensional. In this perspective sometimes their emotions affect and intertwined with many of their cognitive process like thinking, decision making and problem solving abilities.

The present study was conducted to identify the cognitive emotion regulation of male and female teachers with experience above 10 years and below 10 years in sri vijay vidyalaya matriculation higher secondary school, Dharmapuri, Tamilnadu. Hence for this intention survey method was used. 55 male and 55 female teachers were selected, for the sample by adopting stratified random sampling technique. The data was collected by using cognitive emotion regulation questionnaire (CERQ) (Garnefski et al., 2001) was used to assess what teachers tend to think after the experiences of threatening or stressful life events. The data was analyzed by using ' $t$ ' test.

The findings of gender analysis indicates that female teachers possess more cognitive emotion regulation than Male teachers whereas analysis of experience indicates that teachers who are having more than 10 years are having greater cognitive emotional strategy than teachers with less than 10 years experience.
\end{abstract}

Key words: cognitive emotion regulation, teachers, gender, experience.

\section{Introduction}

Teaching and learning are not only concerned with knowledge, cognition and skill. They are emotional practices (Hargreeves, 1998). This does not mean that they are solely emotional practices. Emotion and cognition, feeling and thinking, combine together in all social practices in complex ways. (James 1917; Oately1991)

Emotions are an integral part of education and of organizations more generally. Teachers, learners and leaders all, at various times, worry, hope, enthuse, become bored, doubt, envy, brood, love, feel proud, get anxious, are despondent, become frustrated, and so on. Such emotions are not peripheral to people's lives; nor can they be compartmentalized away from action or from rational reflection within these lives. Emotion, cognition and action, in fact, are integrally connected. Emotion and impulse narrow down the infinite range of choices we have in human action enabling us to choose, to judge, to act, by introducing a bias in the values and preferences that guide us (Oatley, 1991).

The term cognitive coping and cognitive emotion regulations are used as inter changeable terms. Generally speaking both concepts are understood as the cognitive ways of managing the intake of emotionally arousing information.(Thompson,1991) The regulation of emotions through cognition is inextricably associated with human life . Cognitions or cognitive process may help us to manage or regulate emotions, and to keep control over our emotions and or not getting overwhelmed by them, for example during or after the experience of threatening or stressful events.

The review of related literature on cognitive emotion regulation exposes that the foster of cognitive emotion regulation has fascinated many researchers. Currently, there are a number of researchers investigating teachers' emotions in a variety of educational contexts; these researchers highlight how emotions are inextricably linked to teachers' work, development and identity (e.g., Hargreaves 2005), and how those emotions impact teachers' lives (e.g., Liston and Garrison 2004; Zembylas 2005). Yet, to date, there has been no regular effort to critically blend how or what aspects of teacher emotion should be studied and theorized. In fact, researchers are only beginning to examine various expressions of the transactions among teaching and emotions, which recommends that additional research and theorization on teachers' emotions is urgently needed as it will help the educational researcher garner a better understanding of how emotions influence teaching, learning and teachers' lives. Paul A. Schutz and Michalinos Zembylas(2009) In their volume 'Advances in Teacher Emotion Research: the Impact on Teachers ' Lives, 'use a variety of different methodological and theoretical approaches to provide a systematic overview of our current understandings of the role of emotions in teachers' professional lives and work. Exclusively, the authors confer inquiry related to teachers' emotions in educational reform, teacher identity, student involvement, race/class/gender issues, school administration and inspection, emotional labor, teacher burnout and several other related issues.

The study on Cognitive emotion regulation strategies and depressive symptoms: differences between males and females by Nadia Garnefski, Jan Teerds, Vivian Kraaij, Jeroen Legerstee, Tessa van den Kommer (2003) focused that significant differences were found in the strategies Rumination, Catastrophizing and Positive refocusing: women 
reported to use these strategies more often than men. However, no differences were found in the extent to which specific cognitive strategies were related to the reporting of depressive symptomatology. In both groups, higher extents of reporting self-blame, rumination and/or catastrophizing as strategies were strongly related to higher depression scores, whereas higher extents of using positive reappraisal were related to lower depression scores.

N. Garnefski, V. Kraaij, P.Spinhoven (2000) studied negative life events, cognitive emotion regulation and emotional problems of high school students suggested that cognitive coping strategies may be a valuable context of prevention and intervention and play a important role in the relationship between the experience of negative life events and the reporting of symptoms of depression and anxiety.

Objectives of the Study: The objectives of the present study were as follow-

(1) To Study the cognitive emotion regulation of teachers in relation to their gender.

(2) To Study the cognitive emotion regulation of teachers in relation to their experience

Hypotheses: The present study is based on the following hypotheses-

(1) There is no significant difference between cognitive emotion regulation of teachers on the basis of their gender.

(2) There is no significant difference between cognitive emotion regulation of teachers on the basis of their experience.

Research Model-

II. Methodology

Survey method was used in the present study.

\section{Participants-}

Stratified random sampling technique was adopted for the selection of the sample. The sample consisted of 110 teachers comprising 55 male and 55 female who are belonging to more than 10 years and below 10 years from the Sri Vijay Vidyalaya matriculation higher secondary school, Dharmapuri, Tamil Nadu.

\section{Measures-}

The Cognitive Emotion Regulation Questionnaire (CERQ) developed by Garnefski et al., (2001) was used to assess what participants tend to think after the experiences of threatening or stressful life events. The instrument includes nine conceptually distinct scales. These scales all consist of four items referring to what people think after the experience of threatening or stressful life events, ranging from 1 [(almost) never) to 5 (almost) always]. The nine dimensions present in the scale are Self blame, Acceptance, Focus on thought/rumination, Positive refocusing, Refocus on planning, Positive reappraisal, Putting in to perspective, Catastrophizing, Blaming others. Here Acceptance, Positive refocusing, Refocus on planning, Positive reappraisal, Putting in to perspective are more adaptive cognitive emotion regulation strategies whereas Self blame, Focus on thought/rumination, Catastrophizing, Blaming others are less adaptive cognitive emotion regulation strategies. The respondents were instructed to tick mark one out of the five choices as per applicability of $\backslash$ the response to them. The total cognitive emotion regulation score was determined by summing up the scores of all the dimensions.

\section{Statistics used-}

Mean, standard deviation and ' $t$ ' test were used to analyze the data

\section{Result and Discussion}

The table-1 indicates that there is no significant difference between male and female teachers on overall cognitive emotion regulation. But among nine dimensions there was significant difference was occurred in self blame positive refocusing, refocus on planning. Whereas there was no significant difference between male and female teachers in acceptance, rumination, positive reappraisal, putting into perspective, catastrophizing, blaming others. The table indicates that female is having more cognitive emotion regulation than males. From the table we know that male and female teachers differ in using more adaptive strategies like positive refocusing and refocus on planning. And a less adaptive strategy likes self blame. This result is in contrast to the result of Nadia Garnefski, Jan Teerds, Vivian Kraaij, Jeroen Legerstee, Tessa van den Kommer (2003) 
Table-1 : Comparison of the mean cognitive emotion regulation scores of male and female teachers

\begin{tabular}{|c|c|c|c|c|c|}
\hline gender & & $\mathrm{N}$ & Mean & Std. Deviation & $t^{\prime}$ test \\
\hline \multirow[t]{2}{*}{ selfblame } & Male & 44 & 13.09 & 2.835 & \\
\hline & Female & 56 & 11.82 & 2.608 & $2.325 * *$ \\
\hline \multirow[t]{2}{*}{ Acceptance } & Male & 44 & 14.86 & 2.970 & \\
\hline & Female & 56 & 14.68 & 2.961 & 0.310 \\
\hline \multirow[t]{2}{*}{ Rumination } & Male & 44 & 13.75 & 2.634 & 1.145 \\
\hline & Female & 56 & 13.07 & 3.161 & \\
\hline \multirow[t]{2}{*}{ Positive refocusing } & Male & 44 & 14.11 & 2.903 & $2.190 * *$ \\
\hline & Female & 56 & 15.46 & 3.179 & \\
\hline \multirow[t]{2}{*}{ Refocus on planning } & Male & 44 & 16.09 & 2.924 & $2.873 * *$ \\
\hline & Female & 56 & 17.71 & 2.708 & \\
\hline \multirow[t]{2}{*}{ Positive reappraisal } & Male & 44 & 15.02 & 2.799 & 1.317 \\
\hline & Female & 56 & 15.77 & 2.815 & \\
\hline \multirow[t]{2}{*}{ Putting into perspective } & Male & 44 & 10.98 & 3.317 & 0.105 \\
\hline & Female & 56 & 10.91 & 2.993 & \\
\hline \multirow[t]{2}{*}{ Catastrophizing } & Male & 44 & 10.36 & 4.276 & 0.380 \\
\hline & Female & 56 & 10.71 & 4.797 & \\
\hline \multirow[t]{2}{*}{ Blaming others } & Male & 44 & 10.70 & 3.008 & 1.926 \\
\hline & Female & 56 & 9.46 & 3.336 & \\
\hline \multirow[t]{2}{*}{ total } & Male & 44 & 118.98 & 11.441 & 0.252 \\
\hline & Female & 56 & 119.61 & 13.124 & \\
\hline
\end{tabular}

Table-2 Comparison of the mean cognitive emotion regulation scores teachers with more than 10 years experience and less than 10 years experience.

\begin{tabular}{|c|c|c|c|c|c|}
\hline \multicolumn{2}{|l|}{ Experience } & $\mathrm{N}$ & Mean & Std. Deviation & ' $t$ ' test \\
\hline \multirow[t]{2}{*}{ selfblame } & Below 10 & 79 & 12.25 & 2.609 & \\
\hline & Above 10 & 21 & 12.86 & 3.336 & 0.887 \\
\hline \multirow[t]{2}{*}{ Acceptance } & Below 10 & 79 & 15.04 & 2.762 & 1.849 \\
\hline & Above 10 & 21 & 13.71 & 3.452 & \\
\hline \multirow[t]{2}{*}{ Rumination } & Below 10 & 79 & 13.56 & 2.845 & 1.234 \\
\hline & Above 10 & 21 & 12.67 & 3.276 & \\
\hline \multirow[t]{2}{*}{ Positive refocusig } & Below 10 & 79 & 14.87 & 3.102 & 0.021 \\
\hline & Above 10 & 21 & 14.86 & 3.260 & \\
\hline \multirow[t]{2}{*}{ Refocus on planning } & Below 10 & 79 & 16.73 & 2.930 & 1.794 \\
\hline & Above 10 & 21 & 18.00 & 2.646 & \\
\hline \multirow[t]{2}{*}{ Positive reappraisal } & Below 10 & 79 & 15.34 & 2.586 & 0.674 \\
\hline & Above 10 & 21 & 15.81 & 3.614 & \\
\hline \multirow[t]{2}{*}{ Putting into perspectives } & Below 10 & 79 & 10.87 & 3.156 & 0.412 \\
\hline & Above 10 & 21 & 11.19 & 3.060 & \\
\hline \multirow[t]{2}{*}{ Eatastrophizing } & Below 10 & 79 & 10.32 & 4.695 & 1.037 \\
\hline & Above 10 & 21 & 11.48 & 3.958 & \\
\hline \multirow[t]{2}{*}{ Blaming others } & Below 10 & 79 & 9.89 & 3.301 & 0.740 \\
\hline & Above 10 & 21 & 10.48 & 3.027 & \\
\hline \multirow[t]{2}{*}{ otal } & Below 10 & 79 & 118.87 & 11.978 & 0.715 \\
\hline & Above 10 & 21 & 121.05 & 13.862 & \\
\hline
\end{tabular}


Table 2 shows that there was no significant difference in cognitive emotion regulation of teachers with more than 10 years experience and teachers with less than 10 years experience. It is clear from the above table that the teachers with more than 10 years experience are having high cognitive emotion regulation than the teachers who are having less than 10 years experience. The table indicates that teachers with more than 10 years experience are having more score in more adaptive cognitive emotion regulation strategies than the less ad adaptive cognitive emotion regulation strategies. A clear relationship has been shown between the experiences of negative life events, cognitive coping strategies.

\section{Conclusion}

It is evident that when more adaptive cognitive emotion regulation strategies increase, perceived stress decreases. This means that reappraising stressful situations in a positive light and having an optimistic outlook on life ameliorates stress. At the same time it is apparent that as rumination increases, perceived stress increases as well. This means that dwelling on the negative aspects of stressful situations exacerbate the experience of stress. Hence this kind of study is important to the teaching community to know their cognitive emotion regulation strategies and modify their less adaptive cognitive emotion regulation strategies to more adaptive cognitive emotion regulation strategies for the effectiveness in their profession.

\section{References}

[1] Anderson, C. A., Miller, R. S., Riger, A. L., Dill, J. C., \& Sedikides, C. (1994). Behavioral and characterological styles as predictors of depression and loneliness: review, refinement, and test. Journal of Personality and Social Psychology, 66, 549-558.

[2] Arrindell, W. A., \& Ettema, J. H. M. (1986). SCL-90. Handleiding bij een multidimensionele psychopathologie-indicator (Manual for a multidimensional psychopathology-indicator/Dutch translation and adaptation). Lisse: Swets \& Zeitlinger B.V.

[3] Beck, A. T. (1976). Cognitive therapy and the emotional disorders. New York: International Universities Press.

[4] Carver, C. S., Scheier, M. F., \& Weintraub, J. K. (1989). Assessing coping strategies: a theoretically based approach.

[5] Journal of Personality and Social Psychology, 56, 267-283.

[6] Derogatis, L. R. (1977). SCL-90: administration, scoring and procedures manual-I for the (revised) version. Baltimore: John Hopkins University School of Medicine, Clinical Psychometrics Research Unit.

[7] Ellis, A. (1962). Reason and emotion in psychotherapy. New York: Lyle Stuart.

[8] Fivush, R., \& Buckner, J. P. (2000). Gender, sadness, and depression: the development of emotional focus through gendered discourse. In A. Fischer (Ed.), Gender and emotion: social psychological perspectives (pp. 232-253). Cambridge: University Press.

[9] Garnefski, N., Kraaij, V., \& Spinhoven, Ph. (2001). Negative Life events, cognitive emotion regulation and emotional problems. Personality and Individual Differences, 30, 1311-1327.

[10] Gross, J. J. (1999). Emotion regulation: past, present, future. Cognition and Emotion, 13, 551-573.

[11] Ingram, R. E., Miranda, J., \& Segal, Z. V. (1998). Cognitive vulnerability to depression. New York: The Guilford Press.

[12] Nolen-Hoeksema, S. (1987). Sex differences in unipolar depression: evidence and theory. Psychological Bulletin, 101, $259-282$.

[16] Nolen-Hoeksema, S. (1991). Responses to depression and their effects on the duration of depressive episodes. Journal of Abnormal Psychology, 100, 569-582.

[17] Piccinelli, M., \& Wilkinson, G. (2000). Gender differences in depression. Critical review. British Journal of Psychiatry,177, 486492.

[18] Sullivan, M. J. L., Bishop, S. R., \& Pivik, J. (1995). The Pain Catastrophizing Scale: development and validation. Psychological Assessment, 7, 524-532.

[19] Alliance for Excellent Education. (2004). Tapping the potential: Retaining and developing highquality new teachers. (Report). Washington, DC Boler M (1999) Feeling power: emotions and education. Routledge, New York

[20] Crenshaw K (1989) Demarginalizing the intersection of race and sex: A Black feminist critique of antidiscrimination doctrine, feminist theory and antiracist politics. University of Chicago

[21] Legal Foru 139-167.

[22] Hargreaves A (2005) Educational change takes ages: life, career and generational factors in teachers' emotional responses to educational change. Teach Teach Educ 21:967-983

[23] Ingersoll RM (2003) Who controls teachers' work? Cambridge, Massachusetts: Harvard 